\title{
Factors affecting private customers in adopting mobile banking in Vietnam
}

\author{
Thi Thu Huyen Trinh ${ }^{a}$, Hoang Ba Huyen Le ${ }^{b^{*}}$ and Ngan Ha Nguyen ${ }^{a}$
}

${ }^{a}$ Lecturer, Faculty of Economics and Business Administration, Hong Duc University, Vietnam

${ }^{b}$ Dean, Faculty of Economics and Business Administration, Hong Duc University, Vietnam

\section{H R O N I C L E}

\section{Article history:}

Received: January 20, 2020

Received in revised format:

March 252020

Accepted: April 20, 2020

Available online:

April 22, 2020

Keywords:

Affecting factors

Customers' intention

Mobile banking

Vietnam

\section{A B S T R A C T}

The paper aims to identify main factors affecting customers' decision to use mobile banking in Viet Nam. The research team conducted a survey among people who have not yet used and have been using mobile banking at commercial bank branches in three regions: Northern, Middle and Southern of Viet Nam. Based on the theoretical framework from UTAUT2 model combined with Belief and Security Awareness, the authors propose a research model to identify factors affecting intention and behavior of using mobile banking, with 600 questionnaires. The result indicates that several factors were evaluated to be more important than others were. The research points out that "Facilitating condition" did not affect intention of using mobile banking, however "Security awareness" and "Trust" positively affect the customer intention. Moreover, "Security awareness", "Hedonic motivation" and "Social Influence" are factors that have the strongest effects on intention to use mobile banking. In addition, the result also illustrates the relationship between "Culture" with "Benefit Expectancy", "Effort Expectancy" and "Hedonic motivation".

\section{Introduction}

Mobile banking is the conduct of customers and bank by mobile phone or personal digital device connected to the internet (Barnes \& Corbit, 2003). Researches have shown a number of different factors impacting on the intention as well as behavior of using mobile banking. Luarn and Lin (2005), Amin et al. (2008), Yang (2009), Cruz (2010) and Yu (2012) pointed out that risk perception, cost transaction perception, perceived ease of use, reliability awareness are significant factors impacting on intention of using mobile banking. Nevertheless, studies indicate other factors affecting the intention of using mobile banking, such as Perceived favorable service (Brown et al., 2003); Compatibility and Customer's belief (Lee et al., 2003); Social norms (Riquelme \& Rios, 2010) and Demographic (Laukkanen \& Pasanen, 2008; Yu, 2012). In addition, risk perception, cost perception, perceived ease of use and reliability awareness are illustrated to have no effect on the intention to use mobile banking. Studies show that in different contexts, factors are also different; on the other hand, the demographic variable is mainly considered as a control variable, few studies consider it as a moderator variable for each factor impacting intention to use mobile banking. Mobile banking was established in Vietnam in 2010. According to research by Market research firm IDC (2015), Vietnam is one of the top three smartphone growth markets in Southeast Asia with $40 \%$ smartphone usage in 2015 and it is forecasted that in 2021, the proportion of smartphones in Vietnam would increase 3 times compared to 2015. Along with the rapid development of information technology, application of mobile banking has been focused and developed. Despite bringing many benefits, mobile banking is still a relatively new service, a number of customers still do not know and have not used mobile banking. Specific studies in the context of Vietnam in the views of customers are rarely conducted. On that basis, it is very important to study the factors affecting the adoption and use of mobile banking in Vietnamese commercial banks. The finding could contribute to banking system to have accurate solutions to specific customer segments. Based on the above reasons, the authors will use modified model of the unified theory of acceptance and use of technology (UTAUT2) to suit the Vietnamese context; in order to answer the research questions: What factors affect the intention and the behavior of 
using mobile banking in Vietnam, the extent of the influence of each factor, and is there any difference in age and gender for each factor impacting the intention of using mobile banking? Whether or not that factor affecting the intention to use mobile banking influenced by personal cultural factors.

\section{Literature Review}

According to a qualitative study conducted by Lee et al. (2003), the important role of innovation characteristics - relative advantage, compatibility, testing ability and complexity are important factors for intention to use. In addition, a number of studies indicate that several other factors significantly influence the intention to use mobile banking, such as: perceived ease of use, perceived usefulness, perceived risk, perceived cost transaction and perceived reliability (Luarn \& Lin, 2005; Amin et al., 2008; Yang, 2009; Cruz, 2010; Yu, 2012) reliable and relevant information provision (Lee and Chung, 2009) and social norms (Riquelme \& Rios, 2010). UTAUT has been used as theoretical framework for a number of studies, which there have been many extensive or integrated studies of UTAUT. On the basis of UTAUT foundation theory, previous studies show different research results. Specifically:

- Most of the previous studies showed that expected effectiveness is one of the key factors for users to accept and use mobile banking (Yu, 2012; Oliveira et al., 2014; Shaikh \& Karjaluoto, 2015, Alalwan et al., 2016). The expected efficiency implies that users realize the benefits from using mobile banking. It is similar to the usability built from TAM. Benefits that customers can get from using mobile banking may be more than those available from traditional internet-based services or banking services. However, there are a few studies showing that the expected effect does not affect the intention to use mobile banking (Afshan \& Sharif, 2016).

- Deb and Lomo (2014) indicated that effort expectancy is the most significant factor on customers' intention to use mobile banking. Several studies also illustrated that this factor had negative impacts (e.g. Alalwan et al., 2016). In addition to this, other studies like Baptista and Olivera (2015) and Mahfuz et al. (2016) pointed out that there was no effect on customer's intention.

- Intention to use has been dramatically influenced by friends and family members (Singh et al., 2010). In a survey of 158 customers from big banks in Malaysia, Amin et al. (2008) found that mobile banking users were affected by those around them. This can explain why Singh et al. (2010) argued that mobile banking users are not only people who know how to use technology but also a cell of social networks. However, several studies show that social influence does not affect the intention to use mobile banking (Shaikh et al., 2015; Baptista \& Oliveira, 2015; Mahfuz et al., 2016).

- Although Venkatesh et al. (2012), Mahfuz et al. (2016) show that facilitating conditions have positive effects on behavior, most studies show that this factor has no effect on the intention to use mobile banking as Alalwan et al. (2016), Baptista and Oliveira (2015). In previous research on technology, hedonic motivation was found to have a direct effect on the adoption and use of technologies such as Van der Heijden (2004), Brown and Venkatesh (2005). Therefore, Venkatesh et al. (2012) added Hedonic motivation as a consumer predictor of intent to adopt and use technology. Later, many studies have used Hedonic motivation in their studies when studying the intention to accept and use mobile banking such as Baptista and Oliveira (2015), Alalwan et al. (2016). However, Thakur and Srivastava (2013) argued that further investigation is needed for the influence of Hedonics' motivation on the intention to use mobile banking. Mahfuz et al. (2016) debated that hedonic motivation does not affect the intention to use mobile banking. Hsu et al. (2011) stated that price value is one of the important factors for consumers when applying a new technology. The price value has been found to have a positive effect on the intention to use mobile banking (Baptista \& Oliveira, 2015). But there is a negative impact on mobile banking in studies of Chitungo and Munongo (2013). Mahfuz et al. (2016) argued that the price value does not affect the intention to use mobile banking. Several studies showed that customers who have confidence in mobile banking are more willing to accept and use mobile banking (Zhou, 2012; Alalwan et al., 2013; Mahfuz et al., 2016). In addition, Alalwan et al. (2013) also showed that as trust increases, customers will realize that using mobile banking will be easier, more useful and less risky. Safety is the biggest concern in using mobile banking services (Barnes \& Corbitt, 2003; Luarn \& Lin, 2005). Laforet and Li (2005) have identified security issues as the most important factor promoting Chinese consumers' acceptance of mobile banking. In the context of online trading, transactional, network and data attacks or attacks through the unauthorized access of electronic investors' accounts could be a significant barrier preventing the acceptance of practicing online transaction. If Culture were previously not mentioned in the acceptance and use of mobile banking studies, a number of recent studies have considered Culture as a moderator variable in the UTAUT2 model for accepting and using mobile banking (e.g. Baptisca \& Olivera, 2015); or consider factors affecting the intention to use mobile banking in the UTAUT2 model affected by culture (Bankole et al., 2011).

A common interest in the studies is to analyze the impact of age and gender to predict the intention to use mobile banking. Demographics censor the intention to use mobile banking (e.g., Sulaiman et al. (2007) in Malaysia; Yu (2012) in Taiwan). There are studies that consider demographics as a control variable for intention to use, but there are studies that demographics act as moderator variables. Studies on the application of mobile banking often use age and gender as a moderation variable. For example, Cruz et al. (2010) investigated 3585 respondents in Brazil and found that older people perceived mobile banking to be harder to use than younger people; Women are more aware of risks than men (Garbarino \& Strahilevitz, 2004). The 
influence of friends has a greater influence on women in mobile services (Nysveen et al., 2005); men are more likely to use mobile banking than women (Laukkanen \& Pasanen, 2008), and men are more interested in cost of internet access and service than women when using mobile banking (Cruz et al., 2010); Riquelme and Rios (2010) examined 681 people in Singapore and found that the effect of social norms on intention to accept and ease-of-use awareness on the perception of usefulness has a strong impact among women. than men.

\section{Theoretical Framework and Research Model}

\subsection{Theoretical framework}

The theory of unified acceptance and use of technology (UTAUT) was proposed and proved by Venkatesh et al. (2003) to provide a consolidated theoretical foundation on the basis of creating favorable conditions for studying the acceptance and innovation of information systems (IS)/ information technology (IT). The theory proposes 4 main factors: performance expectancy, effort expectancy, social influence and facilitating conditions - which are the direct determinants of IS/ IT behavior intention and final behavior. Venkatesh et al. (2012) developed UTAUT to UTAUT2 based on the previous structure but changed some existing relationships in the original structure and added 3 new relationships, hedonic motivation (pleasure), price value, habit. UTAUT2 abandoned the regulation of "voluntary" variable and added a link between facilitating conditions and intent to use behavior. UTAUT2 is a recent theory that a huge number of researchers apply to their model. This theory integrates several essential elements in previous models; examining the regulatory impact of demographics (gender, age, experience, voluntarily) on factors that have been tested and proven superior to other models (Venkatest et al., 2003). UTAUT2 combines not only the key relationships of UTAUT, but also other relationships that enhance the applicability of UTAUT to consumers. Researchers have formulated different models and theories for technological adoption and use, but most of the initial theories proposed are in the organizational context. Venkatesh et al. (2012) studied the UTAUT2 model in terms of individual customers. In addition, Venkatesh et al. (2012) explained that the intention to use technology is $74 \%$ compared to the original UTAUT of only $56 \%$. Therefore, in the context of studying the factors to forming personal intentions and behaviors for mobile banking, UTAUT2 has chosen to be relevant to research context.

\subsection{Research model and hypotheses}

\subsubsection{Research model}

Based on UTAUT2 combined with the belief and security awareness, the author proposed a research model for the factors affecting the intention and behavior of using mobile banking. In UTAUT2, the author removed the "habit" variable from the research model. Habits are the extent to which people tend to automatically perform behaviors without training (Venkatesh et al., 2012). Habits are less commonly used in mobile banking studies, some of which UTAUT's original research showed that habits do not have a positive effect on the intention to use mobile banking (Mahfuz et al., 2016). In addition, in proposed research model, for the censor variables, "experience" variable is not suitable for the context of using mobile banking. Therefore, the author only investigates the influence of age and gender on structure. Culture can be understood as how people can solve their problems (Schein, 1985 cited in Baptisca and Olivera, 2015). Hofstede (2001) with profound scientific and social influence is the most applied cultural aspect to research in the field of technology. He defines culture as "a collection of programming in mind to distinguish one member from another in society or one type of person". When it comes to culture that is often considered at a macro level, often used for research in different cultures of countries, it is often less used in interpreting behavior on an individual level (Straub et al., 2002 cited in Bankole et al.). However, an individual's behavior is influenced by professional members, different organizations, different social groups. Each individual has a different set value. Therefore, the individuals within each country will greatly differ in the level they agreed. With the above implication, the author examines the impact of culture on individual behaviors using mobile banking. In the author's research model, cultural aspects are considered as elements that indirectly affect the intention to use mobile banking through factors affecting the intention to use the service. Within the scope of the study, the author only examines 3 cultural aspects used in a number of previous studies, that are suitable for the mobile banking field which are individualism, masculinity and uncertainty (Mahfuz et al., 2011). Thus, the structure of study consists of two main contents, which are explaining the factors affecting the intention to use mobile banking and the relationship between factors belonging to cultural factors to factors affecting the intention to use mobile banking.

Performance expectancy $(P E)$ is the belief of customers about using mobile banking services that will help their work to be more effective (Venkatesh et al., 2012).

Effort expectancy $(E E)$ is understood to be the expected effort related to ease of login and use of mobile banking services (Venkatesh et al., 2012).

Social influence (SI) is defined as the impact of other people on the perception of individuals will have a strong impact on their use of mobile banking (Venkatesh et al., 2012). 
Facilitating conditions $(F C)$ is defined as the extent to which an individual believes the resources, they have to support the use of the mobile banking service system (Venkatesh et al., 2012).

Hedonic motivation (HM) is defined as the pleasure of using mobile banking and recognizing several usefulness or effectiveness that is predictable (Venkatesh et al., 2012).

Price value (PV) is understood as the balance of consumer awareness between benefits of mobile banking and costs to use them (Venkatesh et al., 2012).

Trust (TR) is understood as the trust of customers in banking transactions through mobile banking (Ahamed et al, 2017).

Security awareness (SA) is understood as the level of trust that an organization will handle all transactions securely, and keep personal information confidentially (Roca et al., 2009). Individualism (IND) is understood to the extent that individuals emphasize their own needs rather than the needs of a collective and prefer individual actions rather than members of a group (Srite, 2006). Uncertainty avoidance (UA) is the degree to which people of a culture feel uncomfortable with uncertainty and ambiguity (Hofstede, 2001). Masculinity $(M A S)$ is the degree valued as focusing on work goals, assertiveness, efficiency, success as opposed to a culture with softer qualities (Hofstede, 2001). Behavior intention (BI) is the willingness of a person to accept the service (Davis et al., 1989). Use behavior (UB) is as customers regularly using services over a period of time (Al-Qeisi \& Al-Abdallah, 2013) or as the number of transaction and utilities of mobile banking that customers use (Cheng et al., 2008). In this study, the use of mobile banking is considered as the level that mobile banking is used more or less in a certain period of time.

\subsubsection{Research hypotheses}

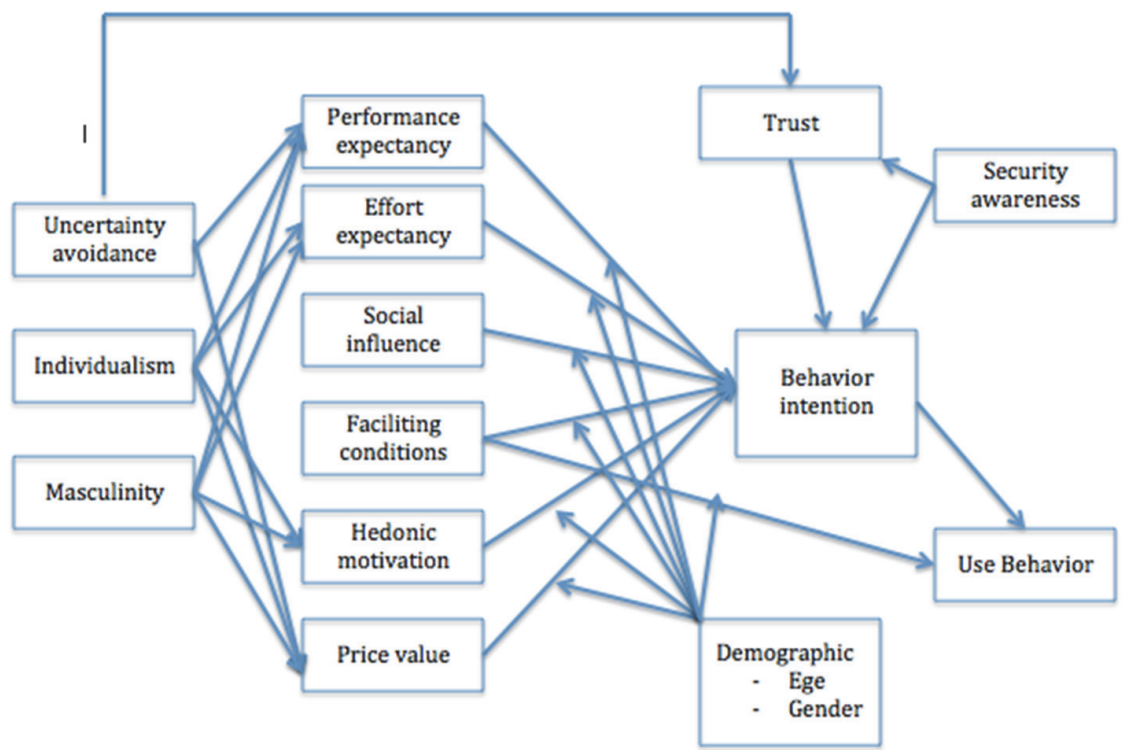

Fig. 1. Proposed Research Model

H1: Performance expectancy positively affects the intention to use mobile banking.

$\mathrm{H} 2$ : Effort expectancy positively influences on the intention to use mobile banking.

$\mathrm{H} 3$ : Social influence positively influences on the intention to use mobile banking.

H4.1: Facilitating conditions positively affect the intention to use mobile banking.

H4.2: Facilitating conditions positively affect the use of mobile banking.

H5: Hedonic motivation positively influences on the intention to use mobile banking.

H6: Price value positively influences on the intention to use mobile banking.

H7: Trust has a positive influence on the intention to use mobile banking.

H8.1: Security awareness positively affects beliefs about mobile banking.

H8.2: Security awareness positively affects the intention to use mobile banking.

H9.1: Individualists will feel positively about performance expectancy when using mobile banking.

H9.2: Individualists will feel positively about effort expectancy when using mobile banking.

H9.3: Individualists will feel positively about hedonic motivation when using mobile banking.

H9.4: Individualists will feel positively about price value of using mobile banking.

H10.1: Uncertainty avoidance is positively related to the perception of performance expectancy when using mobile banking. 
H10.2: Uncertainty avoidance is positively related to the sense of trust when using mobile banking.

H10.3: Uncertainty avoidance is positively related to the perception of price value when using mobile banking.

H11.1: Masculinity is positively related to the perception of performance expectancy when using mobile banking.

H11.2: Masculinity is positively associated with effort expectancy of mobile banking.

H11.3: Masculinity is positively associated with hedonic motivation of mobile banking.

H11.4: Masculinity is positively related to the perception of price value when using mobile banking.

H12.1 to H12.8: factors (respectively by model) affecting the intention to use mobile banking have differences between men and women.

H13.1 to H13.8: factors (respectively by model) affecting the intention to use mobile banking have differences between ages. H14: Intention to use has a positive impact on use behavior of mobile banking.

\subsection{Description of research data}

In this study, with 43 observed variables, the sample size is 600 observations, ensuring the require of sample size according to Hair et al. (2020) and is similar to a number of previous studies in the same field. The number of customers having transactions in Vietnam is very large, covering all provinces and cities nationwide. However, in this study, the authors focused on studying individual customers representing three regions: North, Central and South. Therefore, the sample includes 200 people living in the North, 200 people living in the Central region and 200 people living in the South. The number of votes collected after screening only selected 1 option for all questions about the degree of perceived factors and the votes do not have enough data for analysis, the number of valid votes to use for Quantitative analysis was 540 votes, of which the northern region was 177 votes, the central region was 193 votes and the southern region was 170 votes.

\section{Analysis and Results}

\subsection{Sample statistics}

The proportion of individuals who have feedback and valid for analysis is 540/600 (corresponding to $90 \%$ ). This rate can be considered quite high. This indicates that the quality and the level of questions in the questionnaire is appropriate. In which 200 people have not used mobile banking (accounting for $37 \%$ ) and 340 people (63\%) are using mobile banking. This shows that there is still a high proportion of individual customers who have not used mobile banking yet. Demographic information is shown in Table 1.

Table 1

Table describing demographic characteristics

\begin{tabular}{|c|c|c|c|c|c|}
\hline & Frequency & Ratio (\%) & & Frequency & Ratio (\%) \\
\hline Gender & & & Occupation & & \\
\hline Male & 254 & 47 & Staff & 86 & 15.9 \\
\hline Female & 286 & 53 & Business & 88 & 16.3 \\
\hline Age & & & Public officials & 64 & 11.9 \\
\hline 20 to 30 years old & 140 & 25.9 & Teacher & 56 & 10.4 \\
\hline 31 to 40 years old & 167 & 30.9 & Other & 47 & 8.7 \\
\hline 41 to 50 years old & 142 & 26.3 & Accommodation & & \\
\hline From 51 years old and up & 91 & 16.9 & The North & 177 & 32.8 \\
\hline Level & & & The Central & 193 & 35.7 \\
\hline High school & 120 & 22.2 & The South & 170 & 31.5 \\
\hline College and university & 247 & 45.7 & Income & & \\
\hline Postgraduate & 161 & 29.8 & Under 5 millions/month & 50 & 9.3 \\
\hline Other & 12 & 2.2 & 5 to 10 millions/month & 170 & 31.5 \\
\hline Job & & & 10 to 15 millions/month & 196 & 36.3 \\
\hline Student & 29 & 5.4 & From 15 millions/month & 124 & 23 \\
\hline Housewife & 95 & 17.6 & & & \\
\hline Freelance & 75 & 13.9 & & & \\
\hline
\end{tabular}

\subsection{Analysis results of factors affecting the intention and behavior of using mobile banking}

\subsubsection{Analyzing the reliability of the scale with Cronbach's Alpha coefficient}

Cronbach's Alpha coefficient is used to assess the reliability of the scale before performing the analysis. According to Hair (1988), this coefficient can be used from 0.6 to 0.8 , but if the index is from 0.8 to 1 , the reliability is good. However, if Cronbach's Alpha is too high $(>0.95)$, there is a possibility of excess observed variable appearing in the scale. Meanwhile, the total correlation coefficient of each variable must reach 0.3 or higher to be included in the next analysis (Nunnally and Bernstein, 1994), variables with this coefficient are lower than 0, 3 will be discarded before factor analysis stage. Besides, Cronbach's Alpha if item deleted must be smaller than Cronbach's Alpha coefficient. Running separately the reliability for each scale, we have Cronbach's alpha coefficient of the scales are greater than 0.6 and less than 0.95. However, PE3, EE1, 
PV3, TR3, UA2, IND4, MAS1 observations do not meet the requires because having Cronbach's alpha if item deleted, being larger than Cronbach's alpha coefficient. Therefore, these observations are not eligible for further analysis.

\subsubsection{Explore factor analysis (EFA)}

The analysis results show that from 12 initial factors with 43 observed variables, after eliminating the observed variables which is not conditional, are grouped into 11 factors with 36 observed variables with Eigenvalue value of 1,022 and variance deduction of $61,696 \%$. This means that the factor stops at 1.022 , these 11 factors explain $61.669 \%$ of data variation (Table 2 ). After conducting the factor analysis and preliminary assessment of the reliability of the scale, there is a change in the factor group compared to the original factor. Observed variables PE1, PE2, PE4, PV1, PV2 are grouped into one factor. The content reflects the benefits that mobile banking users expect to receive both in terms of work efficiency and financial efficiency. Thus, this group of factors combined Efficiency expectancy and Price value according to the original theoretical model was renamed as "Benefit expectancy" (BE). This is a new proposed factor compared to the original theoretical model, based on the combination of two factors "Efficiency expectancy" and "Price value" in the proposed research model. The other factors observed have all loading factors greater than 0.5 and do not form new groups. The original hypothesis was changed after combining the two factors "Efficiency expectancy" and "Price value" in the proposed research model from 38 hypotheses to 32 hypotheses.

Table 2

EFA results scale of the study variables

\begin{tabular}{|c|c|c|c|c|c|c|c|c|c|c|c|}
\hline & & & & & & Fac & & & & & \\
\hline & 1 & 2 & 3 & 4 & 5 & 6 & 7 & 8 & 9 & 10 & 11 \\
\hline PE1 & .883 & & & & & & & & & & \\
\hline PE2 & .805 & & & & & & & & & & \\
\hline PE4 & .797 & & & & & & & & & & \\
\hline PV2 & .751 & & & & & & & & & & \\
\hline PV1 & .693 & & & & & & & & & & \\
\hline SA1 & & .785 & & & & & & & & & \\
\hline SA3 & & .782 & & & & & & & & & \\
\hline SA2 & & .632 & & & & & & & & & \\
\hline SA4 & & .629 & & & & & & & & & \\
\hline FC3 & & & .874 & & & & & & & & \\
\hline FC1 & & & .821 & & & & & & & & \\
\hline $\mathrm{FC} 2$ & & & .818 & & & & & & & & \\
\hline HM2 & & & & .855 & & & & & & & \\
\hline HM1 & & & & .853 & & & & & & & \\
\hline HM3 & & & & .700 & & & & & & & \\
\hline MAS2 & & & & & .855 & & & & & & \\
\hline MAS4 & & & & & .826 & & & & & & \\
\hline MAS3 & & & & & .726 & & & & & & \\
\hline EE3 & & & & & & .895 & & & & & \\
\hline EE4 & & & & & & .743 & & & & & \\
\hline EE2 & & & & & & .709 & & & & & \\
\hline UA3 & & & & & & & .862 & & & & \\
\hline UA4 & & & & & & & .817 & & & & \\
\hline UA1 & & & & & & & .689 & & & & \\
\hline SI2 & & & & & & & & .755 & & & \\
\hline SI3 & & & & & & & & .755 & & & \\
\hline SI1 & & & & & & & & .714 & & & \\
\hline IND2 & & & & & & & & & .789 & & \\
\hline IND3 & & & & & & & & & .731 & & \\
\hline IND1 & & & & & & & & & .716 & & \\
\hline TR4 & & & & & & & & & & .742 & \\
\hline TR1 & & & & & & & & & & .739 & \\
\hline TR2 & & & & & & & & & & .693 & \\
\hline BI1 & & & & & & & & & & & .915 \\
\hline BI2 & & & & & & & & & & & .884 \\
\hline BI3 & & & & & & & & & & & .629 \\
\hline
\end{tabular}




\subsubsection{SEM linear structure model}

Among the factors affecting the intention to use mobile banking, "Facilitating Conditions" has a value of sig. $=0.084>0.5$ is not statistically significant at confidence level of $95 \%$. On the other hand, the influence of "Facilitating Conditions" directly on the use behavior is not statistically significant with $95 \%$ confidence (sig. $=0.775$ ). Therefore, removing Facilitating Conditions from the model to retest the SEM structure model. Testing the influence of cultural factors shows that "Individualism" has no effect on "Hedonic Motivation" (value sig. = 0.672) and "Effort Expectancy" (sig value = 0.156). Therefore, the author also excludes these influences to retest the SEM structure model. Eliminating unrelated statistical relationships, conduct the analysis of SEM structure, analysis results are as follows:

The conformity measurement values of TLI, GFI, CFI models are all greater than 0.9; RMSEA $=0.033$ is less than 0.5 , degrees of freedom for the chi square $=1.604$ is less than 0.2 , showing that the SEM structure model is suitable between theory and reality, which is suitable for the market.

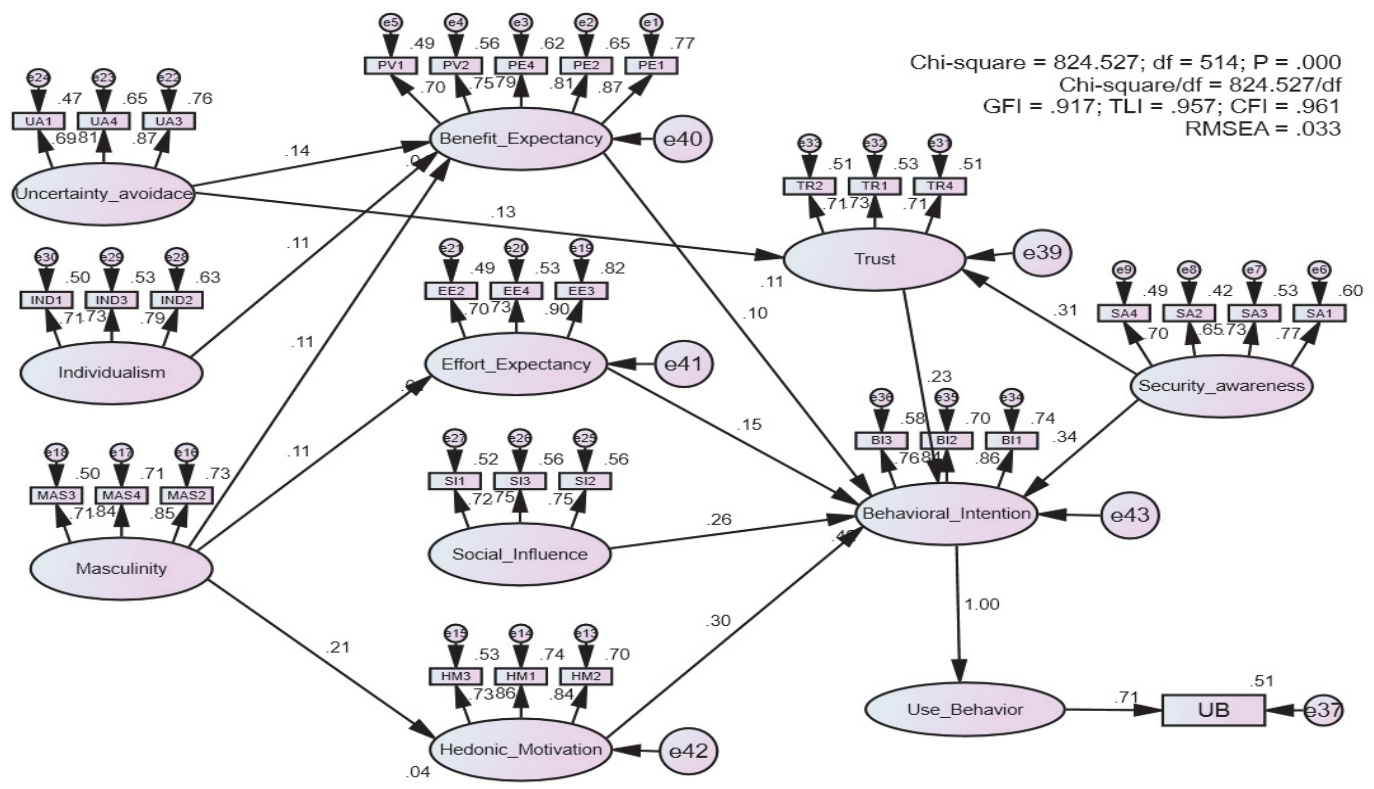

Fig. 2. Results of the second SEM structure

Table 4

SEM regression model coefficients for the second time

\begin{tabular}{lcccccc}
\hline & & & Estimate* & S.E. & C.R. & P \\
\hline Trust & $\leftarrow$ & Security_awareness & .312 & .053 & 5.549 & $* * *$ \\
Benefit_Expectancy & $\leftarrow$ & Uncertainty_avoidance & .141 & .057 & 2.906 & .004 \\
Trust & $\leftarrow$ & Uncertainty_avoidance & .109 & .040 & 2.516 & .012 \\
Benefit_Expectancy & $\leftarrow$ & Individualism & .106 & .068 & 2.152 & .031 \\
Benefit_Expectancy & $\leftarrow$ & Masculinity & .131 & .055 & 2.189 & .029 \\
Effort_Expectancy & $\leftarrow$ & Masculinity & .208 & .056 & 2.285 & .022 \\
Hedonic_Motivation & $\leftarrow$ & Masculinity & .114 & .047 & 4.174 & $* * *$ \\
Behavioral_Intention & $\leftarrow$ & Benefit_Expectancy & .104 & .030 & 2.589 & .010 \\
Behavioral_Intention & $\leftarrow$ & Effort_Expectancy & .152 & .031 & 3.668 & $* * *$ \\
Behavioral_Intention & $\leftarrow$ & Social_Influence & .255 & .043 & 5.665 & $* * *$ \\
Behavioral_Intention & $\leftarrow$ & Hedonic_Motivation & .297 & .038 & 6.981 & $* * *$ \\
Behavioral_Intention & $\leftarrow$ & Trust & .234 & .054 & 4.784 & $* * *$ \\
Behavioral_Intention & $\leftarrow$ & Security_awareness & .343 & .051 & 7.089 & $* * *$ \\
Use_Behavior & $\leftarrow$ & Behavioral_Intention & 1.000 & .078 & 18.402 & $* * *$ \\
\hline
\end{tabular}

Estimate *: Estimate standardized

***: statistically significant

Source: Analysis of survey results

The R2 value of the model of factors affecting the intention to use mobile banking is $42 \%$, the adjusted R 2 is $41.3 \%$. This indicates that $42 \%$ of the variability of the intention to use mobile banking is explained by factors of Benefits expectancy, 
Effort expectancy, Social influence, Hedonic motivation, Trust and Security. Typically, this coefficient must be often over $50 \%$ that the new level of interpretation is considered appropriate. However, the original model UTAUT2 (Not considering the censorship effect of demographic variables) studied by Venkatesh et al. (2012) also illustrated that the adjusted R2 and R2 values were 35\%. Previously, according to Venkatesh et al. (2003), the adjusted R2 and R2 values were only $25 \%$. Therefore, in this study, adjusted R2 and R2 values above 40\%, which are higher compared to the original model, are considered acceptable. The use of mobile banking is explained by $51 \%$ of the intention to use mobile banking. In author's research model, the relationships between the factors affecting the intention to use mobile banking are explanatory, but the relationship between cultural factors to influencing factors only reflects the relationship is related to each other. Therefore, although the R2 value in the model is quite low, the sig value is statistically significant meaning that the factors are related to each other. Regression results of the model are shown in Table 4. The results show that the standardized weights are positive, thus the relationships in the model are positively affected. The sig values are all less than 0.05 meaning that they are statistically significant. This is consistent with the theoretical model proposed. Testing the effects of age and gender on the factors influencing the intention to use mobile banking shows the results in Table 5 and Table 6.

Table 5

Testing the differential effect of age on factors

\begin{tabular}{lcccccccc}
\hline \multirow{2}{*}{ Factor } & \multicolumn{2}{c}{$\mathbf{2 0 - 3 0}$ years old } & \multicolumn{2}{c}{$\mathbf{3 1 - 4 0}$ years old } & \multicolumn{2}{c}{$\mathbf{4 1 - 5 0}$ years old } & \multicolumn{2}{c}{ Over 50 years old } \\
\cline { 2 - 9 } & ES* & Sig. & ES* & Sig. & ES* & Sig. & ES* & Sig. \\
\hline $\mathrm{BE} \rightarrow \mathrm{BI}$ & 0.200 & 0.017 & 0.196 & 0.011 & -0.016 & 0.823 & 0.078 & 0.387 \\
$\mathrm{EE} \rightarrow \mathrm{BI}$ & 0.368 & 0.000 & 0.207 & 0.010 & 0.091 & 0.201 & -0.111 & 0.230 \\
$\mathrm{SI} \rightarrow \mathrm{BI}$ & 0.348 & 0.000 & 0.210 & 0.014 & 0.188 & 0.016 & 0.338 & 0.001 \\
$\mathrm{HM} \rightarrow \mathrm{BI}$ & 0.201 & 0.013 & 0.217 & 0.005 & 0.214 & 0.004 & 0.581 & 0.000 \\
$\mathrm{TR} \rightarrow \mathrm{BI}$ & 0.154 & 0.112 & 0.190 & 0.033 & 0.466 & 0.000 & -0.055 & 0.581 \\
$\mathrm{SA} \rightarrow \mathrm{BI}$ & 0.331 & 0.002 & 0.225 & 0.007 & 0.516 & 0.000 & 0.290 & 0.004 \\
\hline
\end{tabular}

Estimate *: Estimate standardized

Source: Author's data analysis results

Table 6

Testing the differential effect of gender on the factors

\begin{tabular}{lcccc}
\hline \multirow{2}{*}{ Factor } & \multicolumn{2}{c}{ Male } & \multicolumn{2}{c}{ Female } \\
\cline { 2 - 5 } & ES* & Sig. & ES* & Sig. \\
\hline $\mathrm{BE} \rightarrow \mathrm{BI}$ & 0.066 & 0.273 & 0.132 & 0.020 \\
$\mathrm{EE} \rightarrow \mathrm{BI}$ & 0.246 & 0.000 & 0.089 & 0.127 \\
$\mathrm{SI} \rightarrow \mathrm{BI}$ & 0.147 & 0.022 & 0.367 & 0.000 \\
$\mathrm{HM} \rightarrow \mathrm{BI}$ & 0.288 & 0.000 & 0.285 & 0.000 \\
$\mathrm{TR} \rightarrow \mathrm{BI}$ & 0.172 & 0.010 & 0.308 & 0.000 \\
$\mathrm{SA} \rightarrow \mathrm{BI}$ & 0.481 & 0.000 & 0.264 & 0.000 \\
\hline Estimate ${ }^{*}$ Estimate standardized & & & Source: Author's data analysis results
\end{tabular}

After testing the proposed hypotheses, with 540 subjects surveyed, the results demonstrated that in 32 hypotheses, 19 hypotheses were accepted and 13 hypotheses were rejected.

\section{Discussion}

\section{Security awareness}

Surprisingly, security awareness is the strongest factor influencing the intention to use mobile banking $(\beta=0.343)$. Its influence is higher than the main factors in the original model. This can be explained because this is a relatively new banking service in Vietnam. While the impact of risks on other online banking services (ATM, internet banking) is quite large. On the other hand, customers are not allowed to experience the use of services and information related to online suppliers (internet). The study shows results consistent with Yang (2009). However, there are several studies indicating that security and privacy issues have relatively low impacts on the behavior of using online technology (electronic banking) such as Roca et al. (2009).

\section{Hedonic motivation}

As a new element just being included in the model UTAUT2. Research results indicate that hedonic motivation is the second most influential factor after security awareness $(\beta=0.297)$. When users find mobile banking interesting, they will intend to use mobile banking. This shows that the eye-catching of the application, the interface of the application, as well as the convenience of services that bringing a sense of love to customers have a very important influence on the choice of service. However, the difference from the original model is that the hedonic motivation is no different for gender.

\section{Social influence}

This is a factor that has a positive influence on the intention to use mobile Banking $(\beta=0.255)$. This is the third most important factor affecting the intention to use mobile banking (in line with the research of Zhou et al. (2012); Yu (2012); Alam (2014). 
Relatives and important people have a great influence on the individual's intention to use. In fact, the survey results also show that people who are using mobile banking know and use this service through friends and relatives account for a large proportion.

Trust

Initial belief is the fourth most important factor in the factors affecting mobile banking. This is totally appropriate because this is a high-risk service (consistent with previous studies in mobile banking (e.g. Lee et al., 2007; Yang, 2009; Oliveira et al., 2014; Mahfuz et al., 2016; Baptista \& Oliveira, 2016). This study also did not remove "trust" from the research model, once again reaffirming the importance of consumer confidence in mobile banking in terms of Vietnam.

\section{Effort expectancy}

The testing results show that effort expectancy had a positive influence on the intention to use mobile banking. In the view of customers, they believe that the easier it is to use mobile banking, the more they intend to use mobile banking. This is consistent with the original model and mostly studies such as Alam (2014) and Bankole et al. (2011).

\section{Benefits expectancy}

The greater the expected benefit that customers feel, the higher the intention to use mobile. The research results on benefits expectancy and efforts expectancy are quite interesting. These are the two significant factors impacting on acceptance and use of mobile banking (Wang et al., 2008), however in this study, these two factors have had the lowest impact on the intention to use mobile banking. This result is consistent with the context of Vietnam owing to many consumers still do not totally understand the benefits of mobile banking. The price value that customers feel is vague and difficult to measure. Therefore, customers do not appreciate much of the cost they received.

\section{Facilitating condition}

This is a factor that has a conflict with the original model (UTAUT). If the UTAUT model shows that facilitating conditions are factors that influence intention and directly impact on behaviors, this study shows that facilitating condition do not affect the intention to use mobile banking as well as behavior of using mobile banking. This study is also different from previous studies on the intention to use mobile banking such as Faria (2012), Mahfuz et al. (2016). However, the study showed results consistent with other studies that also indicated that facilitating conditions did not affect the intention and behavior of using mobile banking (Baptista \& Oliveira, 2015; Alawan et al., 2016).

\section{Cultural elements}

\section{Masculinity}

The results of this study illustrate that masculinity has a strong relationship to all 3 factors in the proposed model, that are benefit expectancy, effort expectancy and hedonic motivation. That meaning those who are optimistic and assertive tend to perceive higher benefit expectancy, effort expectancy and mobile banking being more interesting. From there their intention to use mobile banking is higher. This is consistent with study of Bankole et al. (2011). With this result, it is suggested that banks when deploying mobile banking should target users who are assertive and strong.

\section{Individualism}

Unexpectedly, individualism has a positive relationship with benefit expectancy. Meaning that, the higher the expression of individualism, the greater the expected benefit. The hypotheses about the relationship of individualism with other factors are almost rejected. This contradicts previous studies (Bankole et al., 2011). Individuals or collectives do not affect whether they feel that mobile banking is easy to use and whether or not they enjoy it. Individualists will be the ones who put their own interests at first, they act not for the benefits of groups or collectives, they will perceive the benefits of mobile banking higher than collectivism. Mobile banking is an application installed on each individual phone, they always expect that the benefits they receive are higher than the costs they spend and they expect the efficiency of mobile banking will be higher.

\section{Uncertainty avoidance}

This study found that individuals who advocate a culture of avoiding high uncertainty are positively associated with benefit expectancy and trust. Two hypotheses in the author's research model regarding the relationship of this factor to benefits expectancy and trust are accepted. People who avoid high uncertainty are positively related to their belief in mobile banking. They will feel the risks that mobile banking brings in a positive direction and they will feel the benefits they received are 
higher than those who always feel uncertain. People who avoid high uncertainty are those who are optimistic and have high confidence in mobile banking. So they will tend to use this service more with people who avoid low uncertainty.

Age and gender

For the 20-30-year-old age group, efforts expectancy, social influence and security awareness are factors that strongly influence the intention to use mobile banking. For the age group of 31-40 years, all factors have an important influence level, the degree of difference between the factors is insignificant, the most powerful factor is security awareness. For the 41-50-yearold age group, security awareness and trust have a great influence, while effort expectancy and benefits expectancy do not affect the intention to use mobile banking. For the age group 51 and older, hedonic motivation and social influence have a great impact; they do not care about benefits expectancy, effort expectancy and trust. Thus, research has shown that young people are more affected by factors than older and middle-aged people. Young people are also use mobile and go shopping online more than the rest, therefore commercial banks should have appropriate solutions every age group. Test results of factors affecting the intention to use mobile banking indicate that men are affected by ease of use (effort expectancy), while women are not affected. This result seems to be contrary to the fact that women are often less technologically skilled than men. However, it is possible to explain why men think that the easier it is to use mobile banking, the more they intend to use it because men are likely being less careful and detailed than women. In addition, they are afraid of small details rather than women. Therefore, they expect to make transactions easier and less manipulated. On the other hand, it is possible that due to security requirements, the use of the application requires more carefulness, which women often surpass men.

\section{Conclusion}

Through quantitative research with AMOS and SPSS, with the context of the study in Vietnam, the study has illustrated that "facilitating conditions" (factors in the original UTAUT model) did not affect intention to use and has proven that "security awareness" and "trust" positively influence the intention to use mobile banking services, including "security awareness", "hedonic motivation", "social influence" are the factors that have the most influence on the intention to use mobile banking (this is also a difference compared to previous studies). Individuals who have individualism, masculine strength, and various uncertainties have different perceptions of ease of use, benefits expectancy, and hedonic motivation for mobile banking. In addition, the study pointed out the difference of age and gender in perceiving factors affecting mobile banking, most notably the youth being more affected by factors and men being mostly affected by the ease of use of the service. The limitation of this study is that it only works in urban areas and represents the North, Central and South. The sample is not highly representative. The author has not studied the factors that directly affect the behavior of using mobile banking. Therefore, this issue provides another research direction for the next research of the authors.

\section{Acknowledgement}

The authors would like to thank the anonymous referees for the comments on earlier version of this paper.

\section{References}

Afshan, S., \& Sharif, A. (2016). Acceptance of mobile banking framework in Pakistan. Telematics and Informatics, 33(2), 370-387.

Al-Jabri, I., \& Sohail, M. S. (2012). Mobile banking adoption: Application of diffusion of innovation theory.

Alalwan, A. A., Dwivedi, Y. K., Rana, N. P., \& Williams, M. D. (2016). Consumer adoption of mobile banking in Jordan: examining the role of usefulness, ease of use, perceived risk and self-efficacy. Journal of Enterprise Information Management, 29(1), 118-139.

Alam, M. M. (2014). Factors affecting consumers' adoption of mobile banking in Bangladesh: an empirical study. TNI Journal of Business Administration and Languages, 2(2), 31-37.

Amin, H., Hamid, M. R. A., Lada, S., \& Anis, Z. (2008). The adoption of mobile banking in Malaysia: The case of Bank Islam Malaysia Berhad (BIMB). International Journal of Business and Society, 9(2), 43.

Baptista, G., \& Oliveira, T. (2015). Understanding mobile banking: The unified theory of acceptance and use of technology combined with cultural moderators. Computers in Human Behavior, 50, 418-430.

Bankole, F. O., Bankole, O. O., \& Brown, I. (2011). Mobile banking adoption in Nigeria. The Electronic Journal of Information Systems in Developing Countries, 47(1), 1-23.

Barnes, S. J., \& Corbitt, B. J. (2003). Mobile banking: Concept and potential. International Journal of Mobile Communications, 1(3), 273-288.

Brown, I., Cajee, Z., Davies, D., \& Stroebel, S. (2003). Cell phone banking: predictors of adoption in South Africa-an exploratory study. International Journal of Information Management, 23(5), 381-394.

Brown, S. A., \& Venkatesh, V. (2005). Model of adoption of technology in the household: A baseline model test and extension incorporating household life cycle, MIS Quarterly, 29(4), 399-426. 
Cheng, D., Liu, G., \& Qian, C. (2008, September). On determinants of user acceptance of internet banking: A theoretical framework and empirical study. In 2008 IEEE Symposium on Advanced Management of Information for Globalized Enterprises (AMIGE) (pp. 1-5). IEEE.

Chitungo, S. K., \& Munongo, S. (2013). Extending the technology acceptance model to mobile banking adoption in rural Zimbabwe. Journal of Business Administration and Education, 3(1).

Cruz, P., Neto, L. B. F., Munoz-Gallego, P., \& Laukkanen, T. (2010). Mobile banking rollout in emerging markets: evidence from Brazil. The International Journal of Bank Marketing, 28(5), 342-371.

Davis, F. D. (1989). Perceived usefulness, perceived ease of use, and user acceptance of information technology. MIS Quarterly, 13(3), 319-340.

Deb, M., \& Lomo-David, E. (2014). An empirical examination of customers' adoption of m-banking in India. Marketing Intelligence \& Planning, 32(4), 475-494.

Faria, M. G. (2012). Mobile banking adoption: A novel model in the Portuguese context. Universidade Nova de Lisboa.

Garbarino, E., \& Strahilevitz, M. (2004). Gender differences in the perceived risk of buying online and the effects of receiving a site recommendation. Journal of Business Research, 57(7), 768-775.

Gerbing, D. W., \& Anderson, J. C. (1988). An updated paradigm for scale development incorporating unidimensionality and its assessment. Journal of Marketing Research, 25(2), 186-192.

Hair, J. F., Black, W. C., Babin, B. J., vàerson, R. E., and Tatham, R. L. (1998), Multivariate data analysis (Vol. 5, No. 3, pp. 207-219), Upper Saddle River, NJ: Prentice hall.

Hsu, C. L., Wang, C. F., \& Lin, J. C. C. (2011). Investigating customer adoption behaviours in mobile financial services. International Journal of Mobile Communications, 9(5), 477-494.

Hofstede, G. (2001), Culture's Consequences: Comparing Values, Behaviors, Institutions, and Organizations across Nations. $2^{\text {nd }}$ ed., Sage Publications, Thousand Oaks, CA.

Laukkanen, T., \& Pasanen, M. (2008). Mobile banking innovators and early adopters: How they differ from other online users?. Journal of Financial Services Marketing, 13(2), 86-94.

Lee, M. S., McGoldrick, P. J., Keeling, K. A., \& Doherty, J. (2003). Using ZMET to explore barriers to the adoption of 3G mobile banking services. International Journal of Retail \& Distribution Management, 31(6), 340-348.

Lee, K. C., \& Chung, N. (2009). Understanding factors affecting trust in and satisfaction with mobile banking in Korea: A modified DeLone and McLean's model perspective. Interacting with Computers, 21(5-6), 385-392.

Luarn, P., \& Lin, H. H. (2005). Toward an understanding of the behavioral intention to use mobile banking. Computers in human behavior, 21(6), 873-891.

Mahfuz, M. A., Hu, W., \& Khanam, L. (2016, May). The Influence of Cultural Dimensions and Website Quality on m-banking Services Adoption in Bangladesh: Applying the UTAUT2 Model Using PLS. In WHICEB, (p. 18).

Mahfuz, M. A., Khanam, L., \& Hu, W. (2016, September). The influence of culture on m-banking technology adoption: An integrative approaches of UTAUT2 and ITM. In 2016 Portland International Conference on Management of Engineering and Technology (PICMET) (pp. 824-835). IEEE.

Nunnally \& Burnstein (1994), Pschychometric Theory, $3^{\text {rd }}$ ed., NewYork, McGraw Hill

Nysveen, H., Pedersen, P. E., \& Thorbjørnsen, H. (2005). Intentions to use mobile services: Antecedents and cross-service comparisons. Journal of the Academy of Marketing Science, 33(3), 330-346.

Oliveira, T., Faria, M., Thomas, M. A., \& Popovič, A. (2014). Extending the understanding of mobile banking adoption: When UTAUT meets TTF and ITM. International journal of information management, 34(5), 689-703.

Singh, S., Srivastava, V., \& Srivastava, R. K. (2010). Customer acceptance of mobile banking: A conceptual framework. Sies journal of management, 7(1), 55.

Shaikh, A. A., \& Karjaluoto, H. (2015). Mobile banking adoption: A literature review. Telematics and Informatics, 32(1), 129-142.

Sulaiman, A., Jaafar, N. I., \& Mohezar, S. (2007). An overview of mobile banking adoption among the urban community. International Journal of Mobile Communications, 5(2), 157-168.

Karjaluoto, H., Riquelme, H. E., \& Rios, R. E. (2010). The moderating effect of gender in the adoption of mobile banking. International Journal of bank marketing, 28(5), 328-341.

Roca, J. C., García, J. J., \& De La Vega, J. J. (2009). The importance of perceived trust, security and privacy in online trading systems. Information Management \& Computer Security.

Thakur, R., \& Srivastava, M. (2013). Customer usage intention of mobile commerce in India: an empirical study. Journal of Indian Business Research, 5(1), 52-72.

Venkatesh, V., Morris, M. G., Davis, G. B., \& Davis, F. D. (2003). User acceptance of information technology: Toward a unified view. MIS quarterly, 27(3), 425-478.

Venkatesh, V., Thong, J. Y., \& Xu, X. (2012). Consumer acceptance and use of information technology: extending the unified theory of acceptance and use of technology. MIS quarterly, 36(1), 157-178.

van der Heijden, H. (2004). User Acceptance of Hedonic Information Systems. MIS Quarterly, 28(4), 695-704.

Wang, G., \& Netemeyer, R. G. (2002). The effects of job autonomy, customer demandingness, and trait competitiveness on salesperson learning, self-efficacy, and performance. Journal of the Academy of Marketing Science, 30(3), $217-228$.

Yang, A. S. (2009). Exploring adoption difficulties in mobile banking services. Canadian Journal of Administrative Sciences/Revue Canadienne des Sciences de l'Administration, 26(2), 136-149. 
Yu, C. S. (2012). Factors affecting individuals to adopt mobile banking: Empirical evidence from the UTAUT model. Journal of Electronic Commerce Research, 13(2), 104.

Zhou, T. (2012). Understanding users' initial trust in mobile banking: An elaboration likelihood perspective. Computers in Human Behavior, 28(4), 1518-1525.

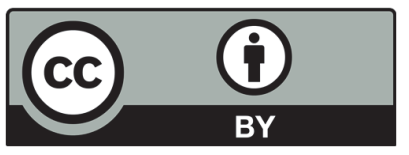

(C) 2020 by the authors; licensee Growing Science, Canada. This is an open access article distributed under the terms and conditions of the Creative Commons Attribution (CC-BY) license (http://creativecommons.org/licenses/by/4.0/). 